\title{
The Accuracy of New and Aged Mechanical Torque Devices Employed in Five Dental Implant Systems
}

\author{
Mehmet Ali Erdem, ${ }^{1}$ Burcin Karatasli, ${ }^{2}$ Onur Dinçer Kose, ${ }^{3}$ Taha Emre Kose, ${ }^{4}$ Erhan Çene, ${ }^{5}$ \\ Serhan Aydın Aya, ${ }^{6}$ and Abdulkadir Burak Cankaya ${ }^{1}$ \\ ${ }^{1}$ Department of Oral and Maxillofacial Surgery, Faculty of Dentistry, Istanbul University, Istanbul, Turkey \\ ${ }^{2}$ Department of Prosthodontics, Faculty of Dentistry, Istanbul University, Istanbul, Turkey \\ ${ }^{3}$ Sultangazi Oral and Mouth Health Care Center, Istanbul, Turkey \\ ${ }^{4}$ Department of Dentomaxillofacial Radiology, Faculty of Dentistry, Recep Tayyip Erdogan University, Rize, Turkey \\ ${ }^{5}$ Department of Statistics, Yildiz Technical University, Istanbul, Turkey \\ ${ }^{6}$ Department of Mechanical Engineering, Faculty of Mechanical Engineering, Istanbul Technical University, Istanbul, Turkey
}

Correspondence should be addressed to Abdulkadir Burak Cankaya; cankaya@istanbul.edu.tr

Received 24 May 2017; Revised 13 September 2017; Accepted 12 October 2017; Published 7 November 2017

Academic Editor: Ayhan Cömert

Copyright (C) 2017 Mehmet Ali Erdem et al. This is an open access article distributed under the Creative Commons Attribution License, which permits unrestricted use, distribution, and reproduction in any medium, provided the original work is properly cited.

\begin{abstract}
Purpose. Friction-style and spring-style torque wrenches are used to tighten implant abutments and prosthetic screws. The mechanical stability of these torque wrenches is crucial for the implant-abutment connection. The purposes of this study were to assess the performance of five brands (Straumann, Zimmer, Implant KA, Bredent, and Biohorizons) of wrench and to evaluate possible changes in applied torque values of aged wrenches. Materials and Methods. Five new and aged wrenches that had been used approximately 250 times in a 1-year period were tested. The torque applied by friction- and spring-style wrenches was measured with a specially designed strain gauge indicator. Descriptive statistics, the one-sample $t$-test, and the independent-samples $t$-test were used to analyze values obtained from all torque wrenches. Results. The accuracy of new and aged torque devices of all brands except Bredent differed significantly from the target values, but the mean values for aged and new wrenches did not differ significantly from each other $(p>0.05)$. Values for the spring- and friction-type torque wrenches deviated from the target values by $11.6 \%$ and $10.2 \%$, respectively. Conclusion. The accuracy of aged torque wrenches is adequate for prosthetic screw tightening, but that of new torque wrenches is unsatisfactory and must be examined carefully before delivery.
\end{abstract}

\section{Introduction}

The success of dental implant therapy may be evaluated in many different ways, including the effectiveness of immobilization, the acceptability of radiographic images, the acceptability of the extent of vertical bone loss, and the absence of surgical and prosthetic complications [1]. Prosthetic procedures commence after successful osseointegration, and many biological and mechanical factors affect the long-term clinical outcomes. Mechanical success is associated directly with continuity of the implant-abutment connection. The most important factors influencing such continuity are the preload applied, the accuracy of implant component integration, and the absence of rotation at the implant-abutment interface [2].
Torque devices are screw-bearing systems that deliver the force necessary to ensure connection of the implant-abutment complex. Torque wrenches are used to preload the abutment screws holding implant components together. Strain preload commences when a torque device is used to initially tighten an abutment screw. Strain on the screw forces the implant and abutment together, allowing the screw to resist external shear loads and fatigue [3]. Creation of an adequate compressive force is the principal manner by which abutment screws are preloaded [4]. Tight stable connections are important to ensure functional continuity $[5,6]$. The required preload depends on various factors, including the applied torque, the alloy of which the screw is 


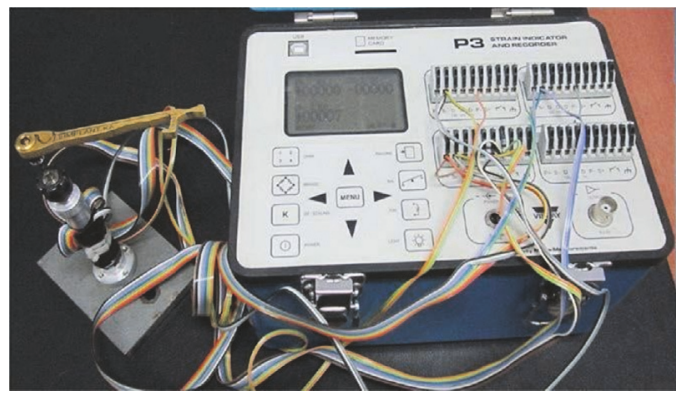

(a)

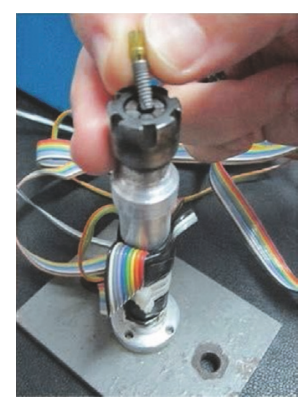

(b)

FIgURE 1: The P3 Strain Indicator and Recorder (a), and positioning of the implant in the device (b).

made, screw head design, the finish of the abutment surface, and the lubricant employed $[7,8]$.

The clamping force affects the mechanical properties of the screw joint [4]. The application of inadequate force may allow the screw to loosen under functional loads. On the other hand, forces that are too great may trigger screw fracture or flattening of the screw threads $[4,5]$. Therefore, the force applied to the abutment screw must be greater than that required for separation [4]. The torque that can be applied is limited by screw durability, the amount of torque that can be delivered at the required speed (mechanical limitations), and the strain that the bone-implant interface can bear (the biological limit) [3]. The torque applied must be that recommended by the manufacturer. The torque applied to an abutment screw by a torque wrench should be within $10 \%$ of the target value. Biohorizons Inc. stated that the optimal torque value should be within $5 \%$ of the target value. Institute Straumann AG reported that their torque wrench was adequate, with torque values within $2 \mathrm{~N} \cdot \mathrm{cm}$ of the target values [9]. Shafi and Mohamed [3] found that torque devices affected the long-term performance of implant-supported prostheses and that the microgap decreased as the applied torque increased.

If the screw joint is inadequate, strain, bending, and compression forces can loosen the screw and the prosthesis [3]. Successful screw joint construction requires consideration not only of mechanical factors, but also of the status of soft tissues around the implant site and the possibility of alveolar bone loss. Insufficient preloading and inadequate screw tightening create stress and compromise stability [3]. In other words, any mismatch between the implant and the abutment delivers forces to peri-implant bony tissue, which can cause locking fractures, locking of the abutment and screw, loosening of the screw and prosthesis, bone microfractures, partial ischemia, loss of crestal bone, peri-implant mucositis, peri-implantitis, and even loss of osseointegration $[3,10]$.

Although one can find many studies of the effect of autoclaving on the accuracy of torque devices, few studies have examined the effects of time-dependent factors.

The aim of the present study was to explore the accuracies of new and aged torque wrenches and to compare the amounts of torque delivered by new devices and devices exposed to aging procedures.

\section{Materials and Methods}

We evaluated five mechanical torque-application devices: the Straumann (Straumann Institute, Waldenburg, Switzerland), the Zimmer (Zimmer Dental, Carlsbad, CA, USA), the Implant KA (Mode Medical, Istanbul, Turkey), the Bredent (KG GmbH \& Co., Senden, Germany), and the Biohorizons (Maestro Dental Implants, Birmingham, AL, USA). We examined five new and five used (250 times over 1 year) devices of each type (thus, 25 devices in total). Ten devices (Straumann, Implant KA) were spring-type and 15 (Biohorizons, Bredent, Zimmer) were friction-type. All devices have handles and holes for the insertion of screwdrivers produced by the manufacturers. We used one implant body, one abutment, and one screwdriver when studying each device. We used new screws for each measurement. We employed a total-bridge strain gauge (P3 Strain Indicator and Recorder; VPG, Micro-Measurements, Wendell, NC, USA) (Figure 1) to measure the torque applied by each device. A four-channel strain measuring device was used to measure torque values. Only three channels were used actively; one was used to measure the mean torque and the other two were used to measure mesiodistal and buccolingual tipping strain. The strain gauges were placed vertically to measure lateral forces and horizontally to measure torsional forces. Lateral forces were measured to eliminate any tipping, thereby ensuring that torque was applied only in the vertical direction.

When strain gauges are attached to equipment to determine stress levels and distributions, the ideal calibration method is to load the equipment at a known stress level and distribution, and to monitor the output of the installed strain gauges. Strain gauge-based transducers were calibrated by applying the appropriate dead-weight load to the torque arm or by using a torque wrench calibration machine and measuring the output. The first step of the calibration process was to amplify and filter the output of the bridge, while using the potentiometer of the amplifier to adjust and balance the output. A known force was then applied to the tube in all three directions, and the output values were recorded.

The implant body, abutment, and screw were attached to the strain gauge, which was set to zero before each test. All measurements were repeated five times; each device was tested in a separate session. All forces were applied by a single experienced operator to the limits recommended by the 
TABLE 1: Minimum, maximum, and mean values for all new and aged wrenches.

\begin{tabular}{|c|c|c|c|c|c|}
\hline $\begin{array}{l}\text { Implant } \\
\text { system }\end{array}$ & $\begin{array}{c}\text { Minimum } \\
\text { value }\end{array}$ & $\begin{array}{l}\text { Maximum } \\
\text { value }\end{array}$ & $\begin{array}{l}\text { Mean } \\
\text { value }\end{array}$ & Std. deviation & $p$ value \\
\hline Biohorizons (aged) & 17.570 & 32.024 & 23.703 & 2.770 & \multirow{2}{*}{$p>0.05(0.814)$} \\
\hline Biohorizons (new) & 19.554 & 27.489 & 23.544 & 1.888 & \\
\hline Bredent (aged) & 17.287 & 45.060 & 30.39 & 1.5069 & \multirow{2}{*}{$p>0.05(0.619)$} \\
\hline Bredent (new) & 21.538 & 38.825 & 29.643 & 0.9666 & \\
\hline Implant KA (aged) & 18.9878 & 27.2064 & 23.1594 & 2.3690 & \multirow{2}{*}{$p>0.05(0.177)$} \\
\hline Implant KA (new) & 18.9878 & 25.2226 & 22.3886 & 1.5173 & \\
\hline Straumann (aged) & 19.27 & 33.16 & 29.8250 & 2.9557 & \multirow{2}{*}{$p>0.05(0.736)$} \\
\hline Straumann (new) & 18.70 & 37.98 & 30.1311 & 3.4132 & \\
\hline Zimmer (aged) & 17.5708 & 31.1740 & 26.2201 & 3.2001 & \multirow{2}{*}{$p>0.05(0.113)$} \\
\hline Zimmer (new) & 15.0202 & 37.4088 & 27.8412 & 3.8774 & \\
\hline
\end{tabular}

TABLE 2: Accuracies of new and aged wrenches.

\begin{tabular}{|c|c|c|c|c|c|c|}
\hline \multirow{2}{*}{$\begin{array}{l}\text { Implant } \\
\text { system }\end{array}$} & \multirow[t]{2}{*}{$\begin{array}{l}\text { Target } \\
\text { value }\end{array}$} & \multirow[t]{2}{*}{$t$} & \multicolumn{2}{|c|}{$\begin{array}{l}\text { 95\% confidence interval of the } \\
\text { difference }\end{array}$} & \multirow{2}{*}{$\begin{array}{c}\text { Mean } \\
\text { difference }\end{array}$} & \multirow[t]{2}{*}{$p$ value } \\
\hline & & & Lower & Upper & & \\
\hline Biohorizons (used) & 30 & -11.363 & -7.4400 & -5.1527 & -6.29642 & $p<0.05$ \\
\hline Biohorizons (new) & 30 & -17.090 & -7.2347 & -5.6755 & -6.4551 & $p<0.05$ \\
\hline Bredent (used) & 30 & 0.358 & -2.5709 & 3.6493 & 0.5391 & $p<0.05$ \\
\hline Bredent (new) & 30 & -0.369 & -2.3513 & 1.6386 & -0.3563 & $p<0.05$ \\
\hline Implant KA (used) & 25 & -3.885 & -2.8184 & -0.8626 & -1.8405 & $p<0.05$ \\
\hline Implant KA (new) & 25 & -8.605 & -3.2377 & -1.985 & -2.6114 & $p<0.05$ \\
\hline Straumann (used) & 35 & -8.754 & -6.3950 & -3.9549 & -5.1749 & $p<0.05$ \\
\hline Straumann (new) & 35 & -7.132 & -6.2778 & -3.4599 & -4.8689 & $p<0.05$ \\
\hline Zimmer (used) & 30 & -5.906 & -5.1007 & -2.4588 & -3.7798 & $p<0.05$ \\
\hline Zimmer (new) & 30 & -2.784 & -3.7592 & -0.5582 & -2.1587 & $p<0.05$ \\
\hline
\end{tabular}

manufacturers. The operator was blinded to values measured by the $\mathrm{P} 3$ strain gauge.

The torque levels recommended by the manufacturers were $35 \mathrm{~N} \cdot \mathrm{cm}$ for the Straumann device; $30 \mathrm{~N} \cdot \mathrm{cm}$ for the Zimmer, Biohorizons, and Bredent devices; and $25 \mathrm{~N} \cdot \mathrm{cm}$ for the Implant KA device. The maximum torques applied with each device were recorded (in $\mathrm{N} \cdot \mathrm{cm}$ ) by a clinician with reference to the strain gauge. We recorded the preload applied to the abutment screw, and the extents of right-to-left and front-to-back tilting. We measured only the preload values applied to the abutment screws. The mean torques delivered by each device were compared in terms of new/used status and accuracy. Descriptive statistics, the one-sample $t$-test, and the independent-samples $t$-test were used to compare the results; the alpha value was set to 0.05 . IBM SPSS 21 software was used for statistical analysis.

\section{Results}

Table 1 shows the target, minimum, maximum, and mean values for all new and aged wrenches. The differences between new and aged wrenches were assessed using independentsamples $t$-test. Although slight differences were apparent between aged and new wrenches, statistical significance was not attained (Table 1).

For all wrenches except new Bredent, the mean values were less than the target values. Table 2 shows the accuracy of aged and new wrenches. The one-sample $t$-test was used to determine whether the wrenches achieved the target values. Except for the Bredent, all aged and new wrenches applied torques that differed significantly from the target values.

Table 3 shows the differences between the mean and target values in $\mathrm{N} \cdot \mathrm{cm}$ and as percentages.

The mean values for new and aged Bredent wrenches differed by only $1 \%$ from the target value which is not statistically different $(p>0.05$; Figure 2$)$.

The mean values for the new and aged Biohorizons wrenches differed by $21 \%$ from the target value $(p<0.05$; Figure 3).

The mean values for the new and aged Straumann wrenches differed by $14.34 \%$ from the target value $(p<0.05$; Figure 4). 
TABLE 3: Differences between mean values and target values in $\mathrm{N} \cdot \mathrm{cm}$ and as percentages.

\begin{tabular}{|c|c|c|c|c|c|}
\hline & Biohorizons & Bredent & Implant KA & Straumann & Zimmer \\
\hline Target value $(\mathrm{N} \cdot \mathrm{cm})$ & 30 & 30 & 25 & 35 & 30 \\
\hline \multicolumn{6}{|l|}{ All wrenches } \\
\hline Mean value & 23.624 & 30.091 & 22.774 & 29.978 & 27.031 \\
\hline Difference & -6.376 & 0.091 & -2.226 & -5.022 & -2.969 \\
\hline Difference\% & -21.253 & 0.305 & -8.904 & -14.348 & -9.898 \\
\hline \multicolumn{6}{|l|}{ Aged wrenches } \\
\hline Mean value & 23.704 & 30.539 & 23.159 & 29.825 & 26.220 \\
\hline Difference & -6.296 & 0.539 & -1.841 & -5.175 & -3.780 \\
\hline Difference\% & -20.988 & 1.797 & -7.362 & -14.786 & -12.599 \\
\hline \multicolumn{6}{|l|}{ New wrenches } \\
\hline Mean value & 23.545 & 29.644 & 22.389 & 30.131 & 27.841 \\
\hline Difference & -6.455 & -0.356 & -2.611 & -4.869 & -2.159 \\
\hline Difference\% & -21.517 & -1.188 & -10.446 & -13.911 & -7.196 \\
\hline
\end{tabular}

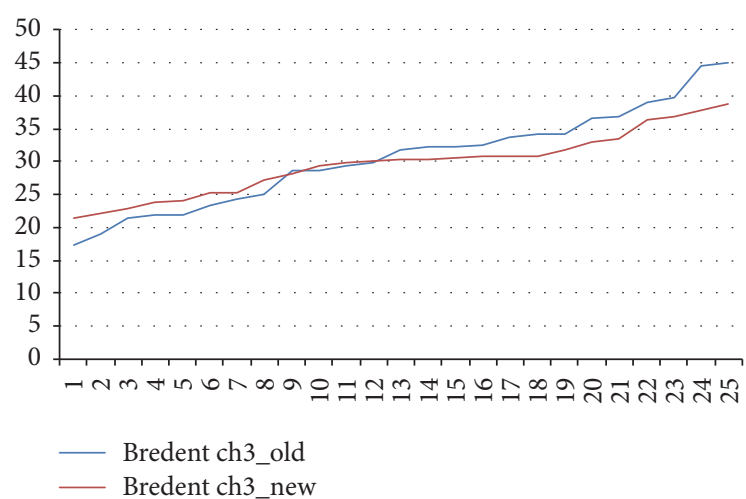

Figure 2: Torques delivered by aged and new Bredent ratchet wrenches.

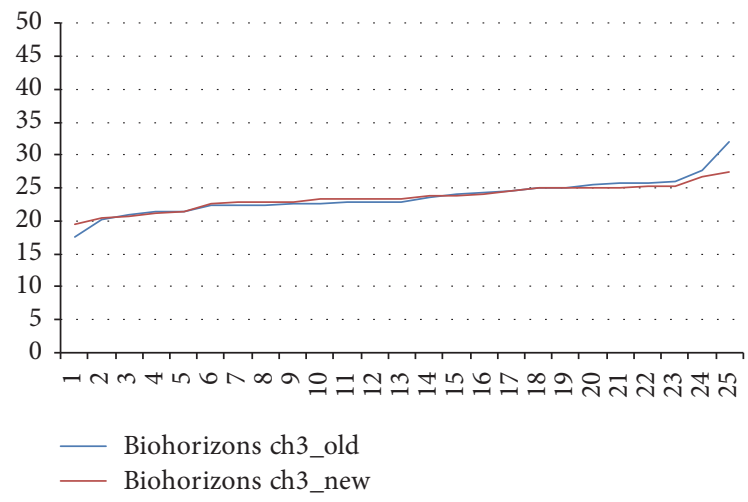

Figure 3: Torques delivered by aged and new Biohorizons ratchet wrenches.

The mean values for the new and aged Implant KA wrenches differed by $8.9 \%$ from the target value $(p<0.05$; Figure 5).

The mean values for new and aged Zimmer wrenches differed by $9.89 \%$ from the target value $(p<0.05$; Figure 6$)$.

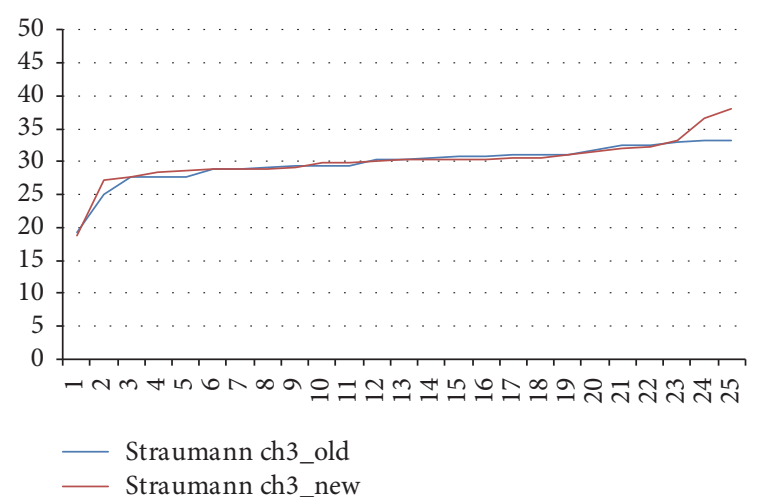

FIGURE 4: Torques delivered by aged and new Straumann ratchet wrenches.

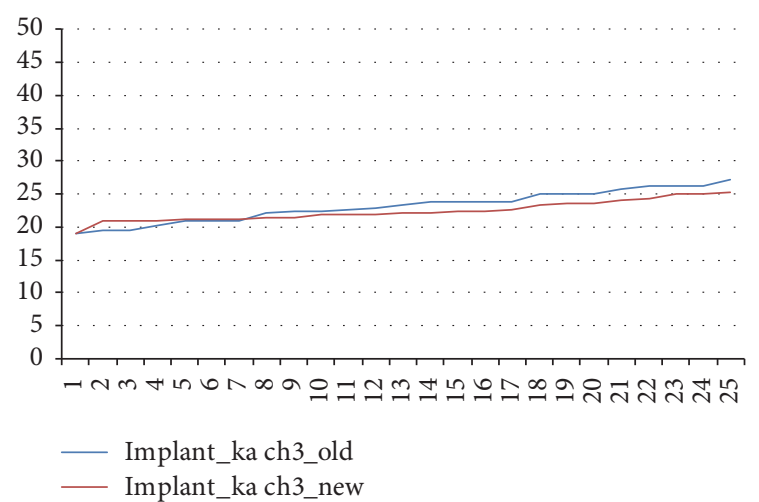

FIGURE 5: Torques delivered by aged and new Implant KA ratchet wrenches.

The spring- and friction-type torque wrenches deviated from the target values by $11.6 \%$ and $10.2 \%$, respectively. 


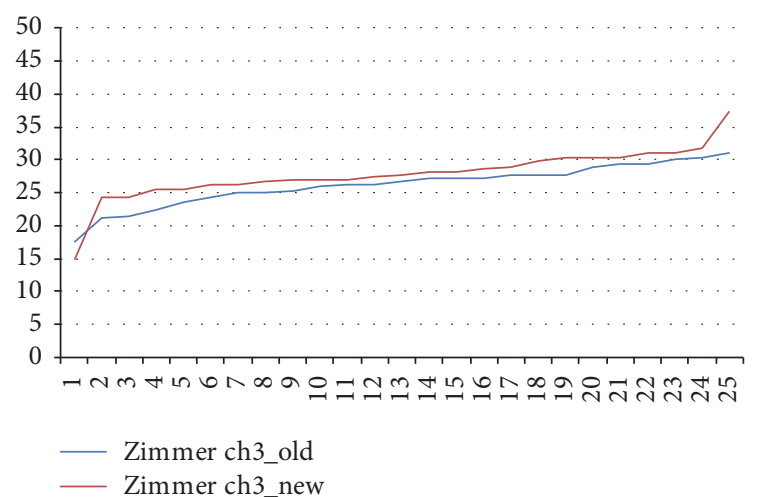

Figure 6: Torques delivered by aged and new Zimmer ratchet wrenches.

\section{Discussion}

Application of the optimum torsional moment to the implant-abutment complex is critical for long-term successful prosthetic implant restoration. The implant-abutment connection loosens over time, resulting in microgaps, bacterial colonization, and peri-implantitis. Over time, microgaps progress to macrogaps. In this situation, the surface connection between the implant and abutment is lost, leading to the exertion of abnormally directed forces to the screw. These phenomena cause complications, such as inflammation/infection of the soft tissues and fracture of the screw [11]. As hand-held drivers do not adequately tighten abutments, the use of mechanical torque-limiting devices has become standard [12]. Application of the optimum torsional force to the implant-abutment connection, ideally using a torquecalibrated ratchet wrench, is crucial [11].

Two types of mechanical torque device are used in implant dentistry: friction- and spring-type devices [13]. The former are also termed toggle-type devices and the latter are also termed beam-type devices [12]. Friction-type devices are hexagonal wrenches with handles that release the applied force when the target torque value is attained. Spring-type devices have scales, and the clinician stops the application of force when the target torque is attained [13].

Strain gauges that measure electrical resistance yield accurate, stable, reliable, and reproducible data $[3,14]$. Such gauges measure strain in different directions. Torsional stress can be measured by connecting four strain gauges to a full-bridge strain indicator. A four-channel strain measuring device was used to measure torque values in this study.

Spring-type wrenches are more accurate than frictiontype devices [15]. Spring-type devices can be used to apply various torques, whereas friction-type devices deliver only the single torque set by the manufacturers [15]. In addition, spring-type wrenches can be used to place various types of implant [16]. Repetitive clinical use and repeated sterilization cycles affect the torques delivered by mechanical wrenches [12]. Friction-type devices may become corroded over time, rendering the applied torques inappropriate [17]. Autoclaving congeals the lubricants present in friction-type devices, causing the applied torque to increase [18].
Spring-type wrenches are not greatly affected by sterilization [12]. In the present study, we examined both types of device and found no significant difference between new and aged torque wrenches of any brand. Spring- and friction-type torque wrenches showed similar deviations from the target torque values ( $11.6 \%$ and $10.2 \%$, resp.).

The torques applied by used and new wrenches differed from the target values, with the exception of the Bredent device. The most accurate new mechanical torque device was the Bredent (1.18\% variation), followed by the Zimmer (7.19\%), Implant KA (10.44\%), Straumann (13.91\%), and Biohorizons (21.51\%) devices. The most accurate used wrench was the Bredent (1.79\%), followed by the Implant KA (7.36\%), Zimmer (12.59\%), Straumann (14.78\%), and Biohorizons (20.98\%) wrenches. Biohorizons wrenches exhibited the greatest variation, deviating by almost $21 \%$ from the target value. Bredent wrenches (used and new) were the most consistent, deviating by only ca. $1 \%$ from the target value. We found no significant difference in torque output between used and new devices. ( $p>0.05$; Table 1). Yilmaz et al. [9] reported that Biohorizons, Zimmer, and Straumann torque wrenches subjected to 100 autoclaving cycles showed no significant difference in applied torque values, and that the torque applied by new and aged torque wrenches was within $10 \%$ of the target values.

The Straumann and Implant KA hand-held mechanical torque devices have spring activated sleeves and calibrated scales. Torque is applied until the required force is obtained. The devices have no mechanical stop; thus, the torque that can be applied is not limited. Çehreli et al. [4] tested 15 Straumann mechanical torque devices divided into three subgroups: new, used 50-200 times, and used 500-1,000 times. A slight decrease in applied torque was evident after 500-1,000 uses. Deformation was always within the elastic limit, suggesting that screw loosening may not be of concern when such devices are employed. Çehreli et al. [4] suggested that the observed decrease in torque was attributable to fatigue in the region where the ratchet is connected to the spring. We found that the mean torque delivered by used Straumann devices was slightly lower than that of new devices, but the difference was not significant $(p=0.736)$. In addition, the mean torque delivered by used and new Implant KA wrenches did not differ significantly ( $p=0.177$; Table 1$)$.

Standlee et al. [19] found that two of three wrenches exerted torques within $10 \%$ of the target values. We found that the torques exerted by the Implant KA and Straumann spring-type devices varied by up to $8 \%$ and $14 \%$, respectively. The torque output of friction-type devices (Bredent, Biohorizons, and Zimmer) varied by up to $0.3 \%, 21 \%$, and $9 \%$, respectively. Vallee et al. [15] found that the torque output values of friction-style devices were below specification, and those of spring-style devices were slightly higher than specification. McCracken et al. [12] compared friction- and springtype wrenches and found that the mean torques delivered did not differ significantly, but that the torques produced by friction-type wrenches varied more than did those produced by spring-type wrenches. With the exception of the Bredent wrench, we found that the mean torques exerted by frictionand spring-type devices were below specification. 
We evaluated the accuracy of various brands of mechanical torque-limiting device, which is affected by clinical use. However, an important limitation of our study is that we had no information on the extent of prior device utilization or the numbers of sterilization cycles to which the wrenches had been subjected. These data were given by the manufacturers.

\section{Conclusion}

Except for one brand, no torque device tested achieved the exact manufacturer-recommended value. The accuracies of new and aged torque wrenches were equivalent, indicating that these wrenches are not easily affected by aging procedures.

We found no significant difference between new and aged devices of any brand. However, and more importantly, the accuracy of the new devices was unsatisfactory and must be carefully examined before delivery.

\section{Conflicts of Interest}

The authors declare that they have no conflicts of interest.

\section{References}

[1] T. Albrektsson, G. Zarb, P. Worthington, and A. R. Eriksson, "The long-term efficacy of currently used dental implants: a review and proposed criteria of success," The International Journal of Oral \& Maxillofacial Implants, vol. 1, no. 1, pp. 11-25, 1986.

[2] M. S. Schwarz, "Mechanical complications of dental implants," Clinical Oral Implants Research, vol. 11, pp. 156-158, 2000.

[3] A. M. A. Shafi and G. F. Mohamed, "The role of torque device in implant retained mandibular overdenture prostheses (in-vivo and in-vitro study)," Cairo Dental Journal, vol. 24, no. 2, pp. 273$287,2008$.

[4] M. C. Çehreli, K. Akça, and E. Tönük, "Accuracy of a manual torque application device for morse-taper implants: A technical note," The International Journal of Oral \& Maxillofacial Implants, vol. 19, no. 5, pp. 743-748, 2004.

[5] H. Rajatihaghi, J. Ghanbarzadeh, N. Daneshsani, R. Sahebalam, and M. Nakhaee, "The accuracy of various torque wrenches used in dental implant systems," JDMT, vol. 2, no. 2, pp. 38-44, 2013.

[6] K. L. Goheen, S. G. Vermilyea, J. Vossoughi, and J. R. Agar, "Torque generated by handheld screwdrivers and mechanical torquing devices for osseointegrated implants," The International Journal of Oral \& Maxillofacial Implants, vol. 9, no. 2, pp. 149-155, 1994.

[7] E. A. McGlumphy, D. A. Mendel, and J. A. Holloway, "Implant screw mechanics.," Dental Clinics of North America, vol. 42, no. 1, pp. 71-89, 1998.

[8] R. L. Burguete, R. B. Johns, T. King, and E. A. Patterson, “Tightening characteristics for screwed joints in osseointegrated dental implants," The Journal of Prosthetic Dentistry, vol. 71, no. 6, pp. 592-599, 1994.

[9] B. Yilmaz, E. L'Homme-Langlois, F. M. Beck, and E. McGlumphy, "Effect of long-term steam autoclaving on changes in torque delivery of spring- and friction-type torque wrenches," Journal of Prosthetic Dentistry, vol. 115, no. 6, pp. 718-721, 2016.

[10] P. Vigolo, Z. Majzoub, and G. Cordioli, "Measurement of the dimensions and abutment rotational freedom of gold-machined $3 i$ UCLA-type abutments in the as-received condition, after casting with a noble metal alloy and porcelain firing," Journal of Prosthetic Dentistry, vol. 84, no. 5, pp. 548-553, 2000.

[11] O. Dincer Kose, B. Karatasli, S. Demircan et al., "In vitro evaluation of manual torque values applied to implant-abutment complex by different clinicians and abutment screw loosening," BioMed Research International, vol. 2017, pp. 1-9, 2017.

[12] M. S. McCracken, L. Mitchell, R. Hegde, and M. D. Mavalli, "Variability of mechanical torque-limiting devices in clinical service at a US dental school," Journal of Prosthodontics, vol. 19, no. 1, pp. 20-24, 2010.

[13] M. D. Scherer and E. A. McGlumphy, "A universal torque wrench system," Journal of Prosthetic Dentistry, vol. 108, no. 6, pp. 401-403, 2012.

[14] A. S. Khan and X. Wang, "Strain measurements and stress analysis.metal-foil resistance strain gages," in Strain Measurements and Stress Analysis, Chapter 2, pp. 30-40, Prentice Hall Inc, New Jersey, USA, 2001.

[15] M. C. Vallee, H. J. Conrad, S. Basu, and W.-J. Seong, "Accuracy of friction-style and spring-style mechanical torque limiting devices for dental implants," Journal of Prosthetic Dentistry, vol. 100, no. 2, pp. 86-92, 2008.

[16] A. Luu and E. Tamiko, "Adapting the ITI torque driver for use with other implant systems.," The Journal of Prosthetic Dentistry, vol. 81, no. 6, p. 732, 1999.

[17] J. Gutierrez, J. I. Nicholls, W. J. Libman, and T. J. Butson, "Accuracy of the Implant Torque Wrench Following Time in Clinical Service," International Journal of Prosthodontics, vol. 10, no. 6, pp. 562-567, 1997.

[18] M. Mahshid, A. Saboury, A. Fayaz, S. Jalil Sadr, F. Lampert, and M. Mir, "The effect of steam sterilization on the accuracy of spring-style mechanical torque devices for dental implants," Clinical, Cosmetic and Investigational Dentistry, vol. 4, pp. 2935, 2012.

[19] J. P. Standlee, A. A. Caputo, M.-Y. J. Chwu, and T. T. Sun, "Accuracy of Mechanical Torque-Limiting Devices for Implants," The International Journal of Oral \& Maxillofacial Implants, vol. 17, no. 2, pp. 220-224, 2002. 


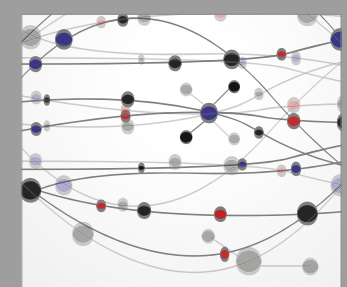

The Scientific World Journal
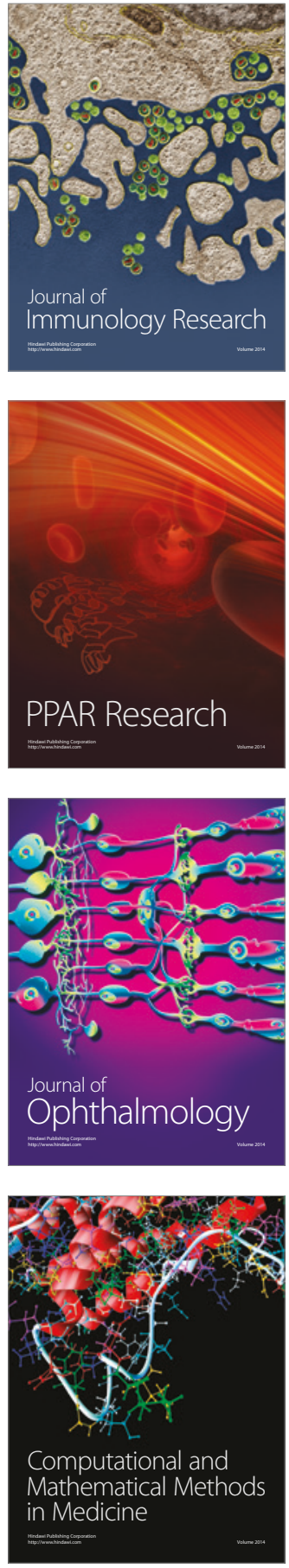

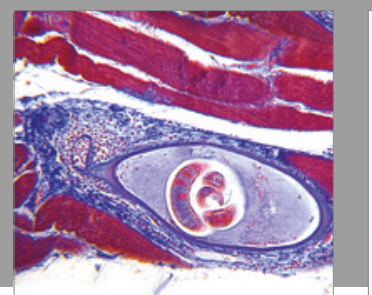

Gastroenterology Research and Practice
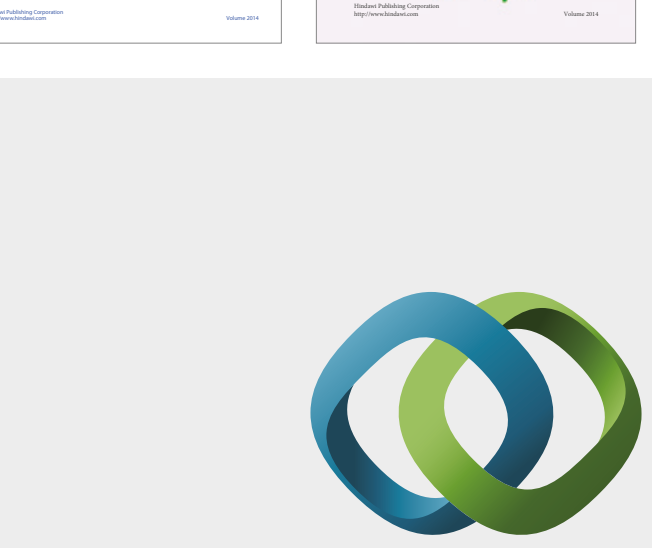

\section{Hindawi}

Submit your manuscripts at

https://www.hindawi.com
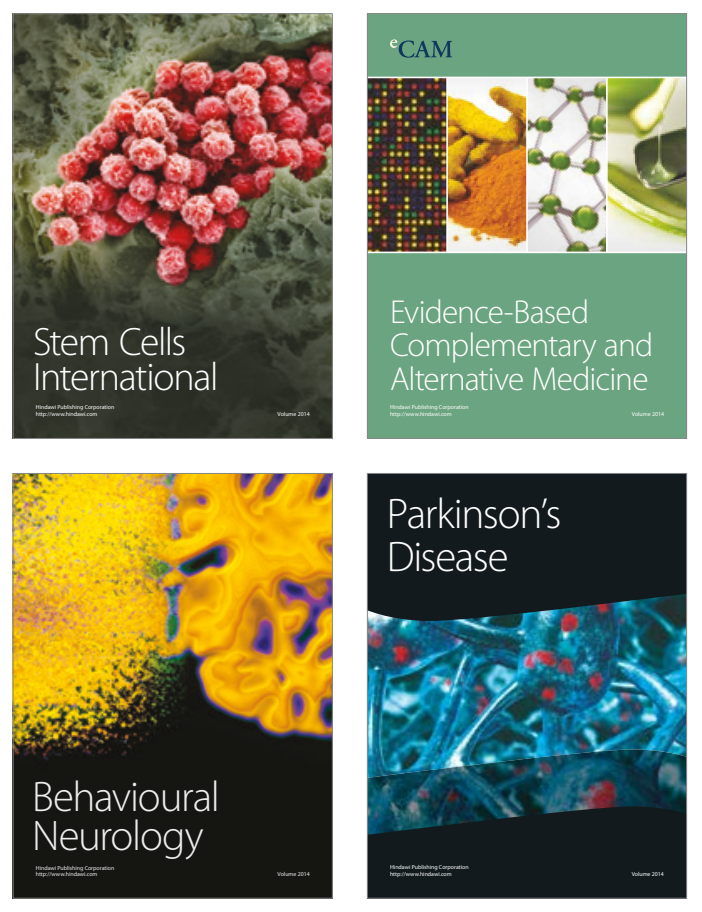
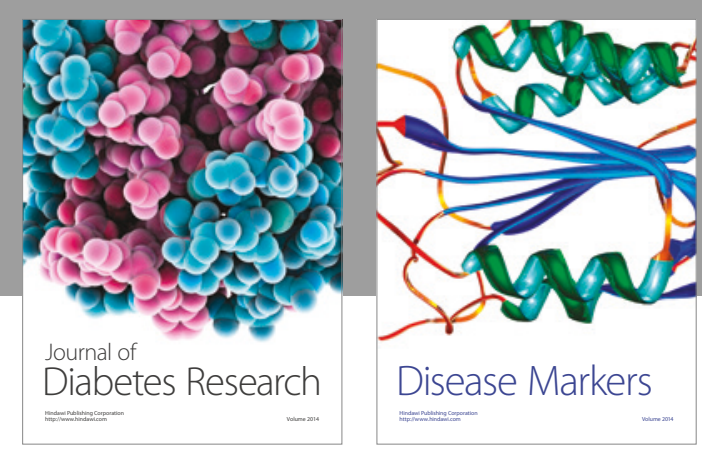

Disease Markers
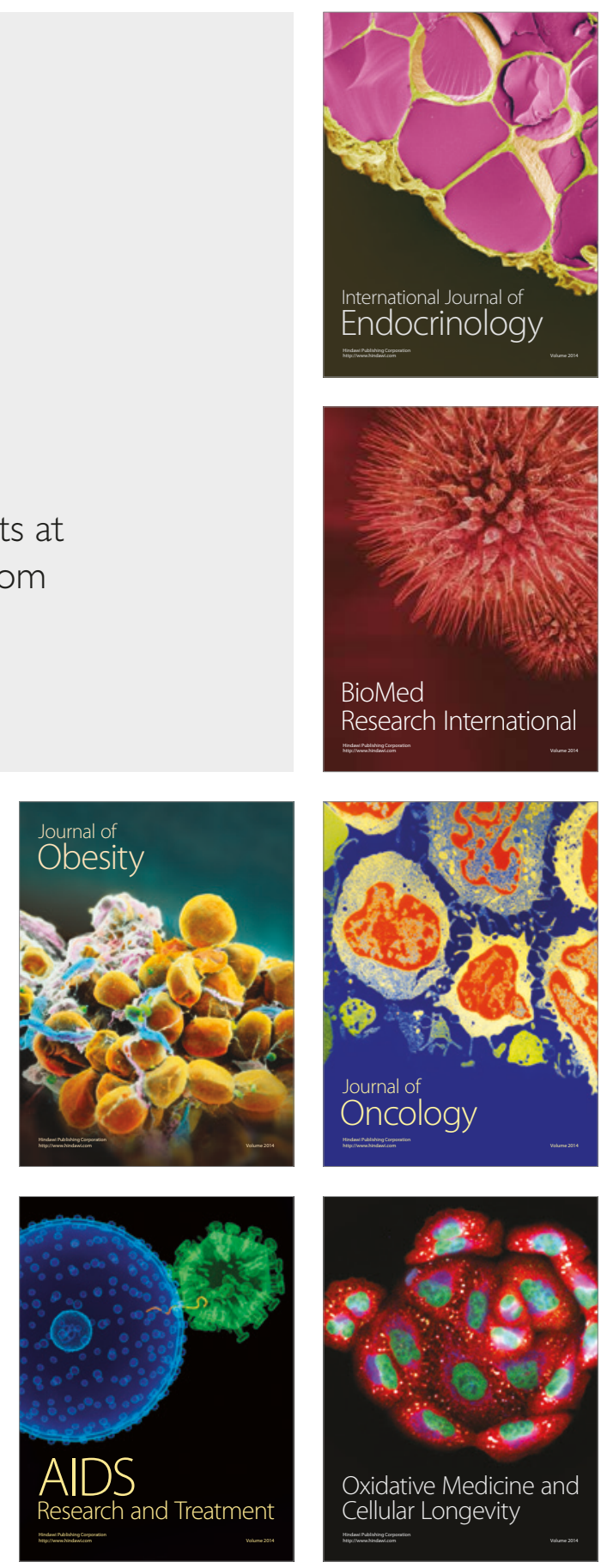